[17] Schröder, F. H., Hugosson, J., Roobol, M. J., Tammela, T. L. J., Ciatto, S., Nelen, V. et. al. (2009). Screening and Prostate-Cancer Mortality in a Randomized European Study. New England Journal of Medicine, 360 (13), 1320-1328. doi: http://doi.org/10.1056/nejmoa0810084

[18] Zhane, A. K. (2000). Ways to improve inpatient care during the period of health care reform. Saint Petersburg, 23.

[19] Pavlov, Yu. V. (2002). Medical and organizational bases of improvement of work of hospitals of intensive treatment in the conditions of reforming of inpatient care. Saint Petersburg, 40.

\title{
DIAGNOSTIC VALUE OF MORPHOLOGICAL CHANGES IN GASTROESOPHAGEAL REFLUX DISEASE IN BIOPSY MATERIAL OF THE DISTAL ESOPHAGUS IN ADOLESCENTS SICKLY WITH ACUTE RESPIRATORY DISEASES
}

\author{
Olena Zhuravel \\ Department of Pediatrics No. 1 \\ A. A. Bogomolets National Medical University \\ T. Shevchenko blvd., 13, Kyiv, Ukraine, 01601 \\ Tetyana Pochinok \\ Department of Pediatrics No. 1 \\ A. A. Bogomolets National Medical University \\ T. Shevchenko blvd., 13, Kyiv, Ukraine, 01601 \\ Tamara Zadorozhna \\ Department of Pathological \\ Institute of Pediatrics, Obstetrics and Gynecology of NAMS of Ukraine \\ 8 Platona Mayborody str., Kyiv, Ukraine, 04050 \\ Tetyana Archakova \\ Department of Pathological \\ Institute of Pediatrics, Obstetrics and Gynecology of NAMS of Ukraine \\ 8 Platona Mayborody str., Kyiv, Ukraine, 04050 \\ Valentyna Zamula \\ Children's Clinical Hospital No. 9 Podolsk district \\ 1/7 Kopilivska str., Kyiv, Ukraine, 04073
}

\footnotetext{
Abstract

The article dedicated to the problem of the diagnostic value of morphological changes in gastroesophageal reflux disease in the biopsy of the distal esophagus in pubertal children of childbearing age.

Aim of the research is to investigate the diagnostic value of morphological changes in gastroesophageal reflux disease in esophageal biopsy material in adolescents sickly with acute respiratory diseases.

Methodology. The objective of the study was achieved through examination of 90 adolescents (10 to 16 years old, average age 13.1 \pm 3.54 years) kept under observation at the Children's Clinical Hospital No. 9 of Kyiv and on the basis of the Department of Pediatrics No. 1 Center of Primary Health Care No. 4 of the Desnianskyi district of Kyiv. All adolescents belonged to the group of sickly with a number of respiratory diseases averaging 6-8 times a year, lasting from 8 to 18 days (on average 12.8 \pm 5.41 days). All children have undergone endoscopic examination of the esophagus, stomach and duodenum with the esophagus mucosa biopsy using the OLYMPUS GIF-P3 flexible fiberscope.
} 
Results. It was found that the least valuable diagnostic feature in the morphological examination of the mucous membrane of the distal esophagus in the pain-causing children with GERD was thickening of the epithelium with a sensitivity of $13,0 \%$, a specificity of $96.0 \%$, and total value of $65.0 \%$. It has been proved that hyperplasia of cells of the basal layer of the mucous membrane of the distal esophagus at the GERD in the infected children is $46.7 \%$ (specificity $-93.3 \%$, the total value is $75.6 \%$ ). Increase in the number of papillae and their prolongation in $33.3 \%$ cases (sensitivity $-33.3 \%$, specificity $-93.3 \%$, overall diagnostic value $-70.8 \%$ ).

Conclusion. The peculiarity of the morphological manifestations of GERD in childbearing children is dystrophic changes in keratocytes in the superficial parts of the multilayer squamous epithelium, which are detected at $100.0 \%$ of patients (specificity is $93.3 \%$, total value is $96.8 \%$ ), with parakeratosis centers at $13.3 \%$ of cases. It has been shown that a frequent and diagnostically valuable indication is inflammatory infiltration of the esophageal mucosa, which are verified in all cases $(100.0 \%$, with dilatation and hyperemia in $46.7 \%$ of patients (specificity $-40.0 \%$, total value $-81.3 \%$ ).

Keywords: gastroesophageal reflux disease, childhood fever, distal esophagus, morphological changes.

\section{Introduction}

Gastroesophageal reflux disease (GERD) is a chronic relapsing disease with a spontaneous regular discharge of the gastric and/or duodenal contents into the esophagus, leading to the lower esophagus affection $[1,2]$. Incidence of the disease from 1 to 12 years and further increases reaching the maximum at the age of 16-17 [3,4]. Although there are no large prospective population surveys in this area, it is anticipated that many children are diagnosed with GERD in adolescence and teen-age [5].

For the first time, the modern term GERD was proposed by M. Rossetti in 1966 [6]. The current general consensus determines the GERD in the occurrence of endoscopically indentifiable lesions, cracks, ruptures of the esophagus mucosa immediately above the gastroesophageal junction. Detection of esophagitis is specific for the GERD in 90-95\%, but with a sensitivity of 50\% [7].

The endoscopic method is the main method of diagnostics of the GERD which allows confirming the occurrence of reflux esophagitis, assessing its severity and make sampling for histodiagnosis and bacterioscopy [8]. For the endoscopic classification of esophagitis, the Hetzel-Dent (2016) [9], Savary-Miller classifications [10, 11] in the Carisson [12] and Los Angeles (2011) [10, 13-14] modifications are used in the academic research of adults and children. Endoscopically normal esophagus mucosa, however, does not exclude the diagnosis of the GERD or esophagitises of other etiologies [15]. The results of histology are affected by sampling faults, the heterogeneity of inflammatory changes, the lack of standardization of the biopsy site and the interpretation of morphological data. Therefore, these observations are important and still remain the focus of research [16].

There are also recent works dealing with the role of infectious agents, in particular persistent infection, in the development of chronic esophagitises and the GERD [17-19]. That is, the data of research conducted in recent years, testify to the etiological heterogeneity of chronic esophagitises, which may involve at least three factors in their development - pathological gastroesophageal reflux (GER), food and respiratory allergy, chronic infection. The above urges study of the esophagus mucosa biopsy data in adolescents sickly with acute respiratory diseases (ARD) against the background of the GERD.

\section{Aim of the research.}

Research objective is to investigate the diagnostic value of morphological changes in gastroesophageal reflux disease in esophageal biopsy material in adolescents sickly with acute respiratory diseases.

\section{Material and methods of the research}

The study was conducted for the period 2015-2018. The objective of the study was achieved through examination of 90 adolescents (10 to 16 years old, average age $13.1 \pm 3.54$ years) kept under observation at the Children's Clinical Hospital No. 9 of Kyiv and on the basis of the Department of Pediatrics No. 1 Center of Primary Health Care No. 4 of the Desnianskyi district of Kyiv. All adolescents belonged to the group of sickly with a number of respiratory diseases averaging 6-8 times a year, lasting from 8 to 18 days (on average $12.8 \pm 5.41$ days). 
All children have undergone endoscopic examination of the esophagus, stomach and duodenum with the esophagus mucosa biopsy using the OLYMPUS GIF-P3 flexible fiberscope.

In order to solve the tasks, the general histological method was used in the study. The material was treated through paraffin embedding, the sections were stained with hematoxylin \& eosin (the technique gives a general idea of the organ structure, reveals well all cellular elements and some non-cellular structures) and picro-fuchsine following van Gieson method (the technique allows to detect the connective tissue; the collagen fibers of the connective tissue when stained with picro-fuchsine have a red colour, muscular and elastic tissues have brownish-yellow or yellow-green colour, the nuclei have dark brown colour).

The statistical processing of the research results was made using the STATISTICA 10.0 package (StatSoft Inc., USA). The objective parameters were used to describe the informativeness of the morphological study, which were determined as the operational characteristics of the tests. The most important operational characteristics of the diagnostic methods included sensitivity (Se), specificity (Sp), diagnostic accuracy (E, efficacy). The probability of the difference in frequency distribution was determined by Fisher's criterion $\chi 2$.

\section{Results}

Research findings and their consideration. In the study of morphological features of the esophagus mucosa among biopsy material of 60 children, the following criteria were evaluated:

1) occurrence of erosion (Fig. 1, 2);

2) thinning of the epithelium (Fig. 3);

3) thickening of the epithelium (Fig. 4);

4) dystrophy of the epithelium (Fig. 5);

5) papillae elongation (Fig. 6);

6) inflammatory infiltration (Fig. 7);

7) basal cell hyperplasia (Fig. 8);

8) dilatation and plethora of vessels.

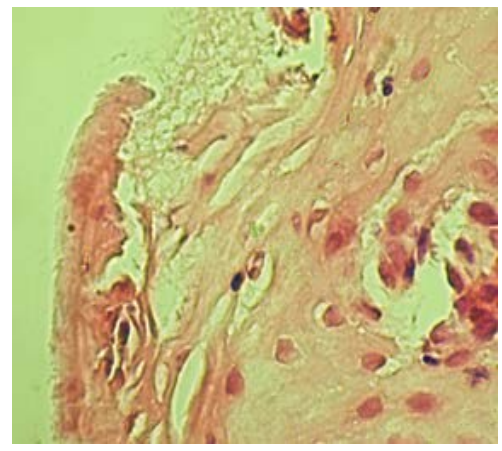

Fig. 1. Esophagus mucosa of sickly children with the GERD. Mucosa erosion.

Hematoxylin \& eosin $(10 \times 40)$

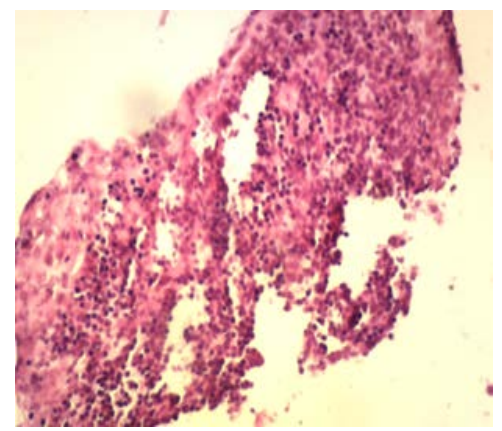

Fig. 2. Esophagus mucosa of sickly children with the GERD. Deep erosion. Hematoxylin \& eosin $(10 \times 10)$ 


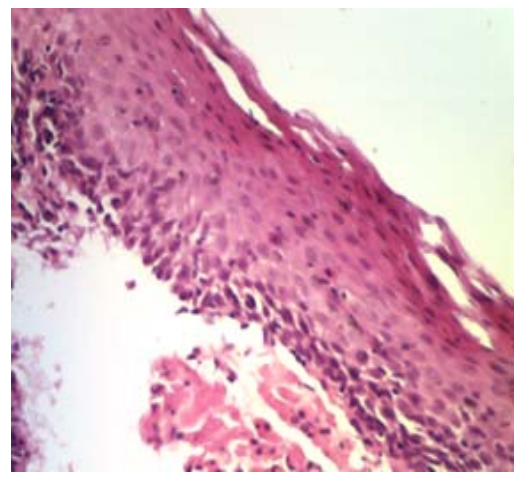

Fig. 3. Esophagus mucosa of sickly children with the GERD. Focal thinning of squamous epithelium. Hematoxylin \& eosin $(10 \times 10)$

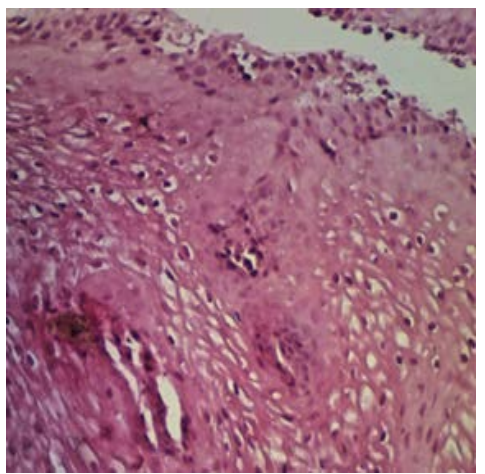

Fig. 4. Esophagus mucosa of sickly children with the GERD. Focal thickening of squamous epithelium. Hematoxylin \& eosin $(10 \times 10)$

The activity of the GERD in sickly children with acute respiratory diseases (Fig. 1, 2) was characterized by erosive defects of the esophagus mucosa of varying degrees of severity with the death of a small number of superficial cells of the stratified squamous epithelium (Fig. 1), in some cases extending to the basal layer of the esophagus mucosa - deep erosion (Fig. 2).

Morphological changes in the stratified squamous epithelium of the distal esophagus were detected as focal thinning (Fig. 3), areas of thickening - moderate or pronounced (Fig. 4), alternating areas of thinning with thickening focuses with dystrophic changes (Fig. 5).

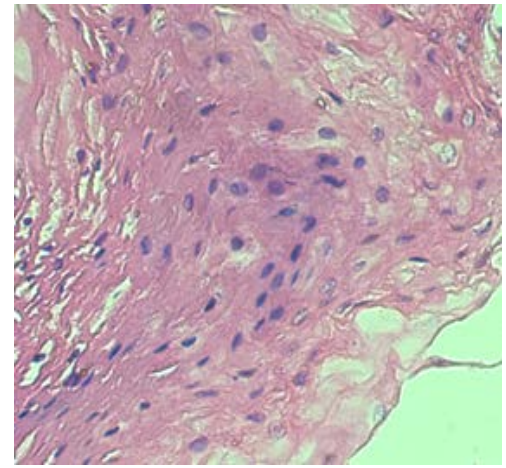

Fig. 5. Esophagus mucosa of sickly children with the GERD. Dystrophy of superficial cells of the stratified squamous epithelium. Hematoxylin \& eosin $(10 \times 10)$

In all cases, signs of dystrophic changes in the epithelium and keratocytes were observed in the biopsy material (Fig. 5). In some of them, balloon dystrophy of the epithelium (Fig. 9), micro- 
focuses of parakeratosis, hyperplasia of cells of varying degrees of severity (Fig. 8) with esophagus mucosa papilla elongation (Fig. 6) were observed.

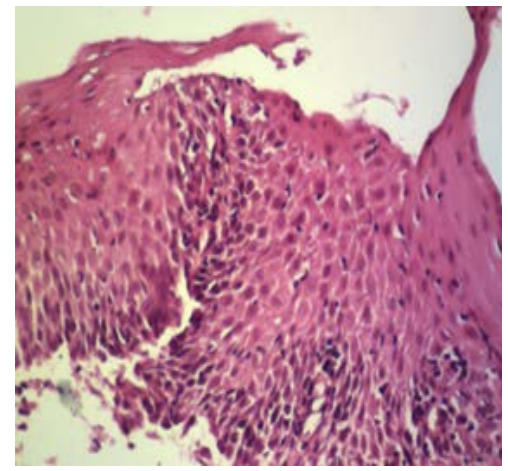

Fig. 6. Esophagus mucosa of sickly children with the GERD. Esophagus mucosa papillae elongation. Hematoxylin \& eosin $(10 \times 10)$

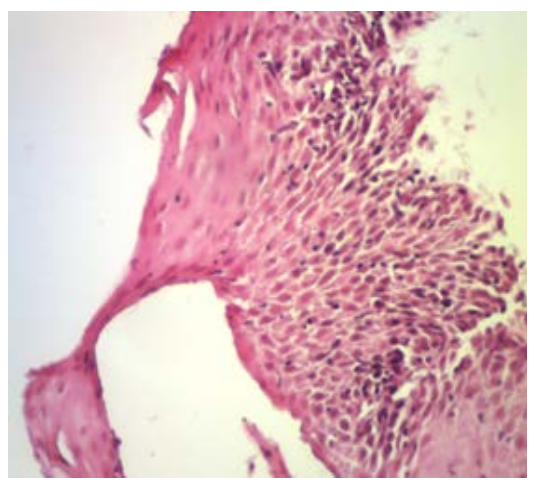

Fig. 7. Esophagus mucosa of sickly children with the GERD. Inflammatory infiltration of the stratified squamous epithelium. Hematoxylin \& eosin $(10 \times 10)$

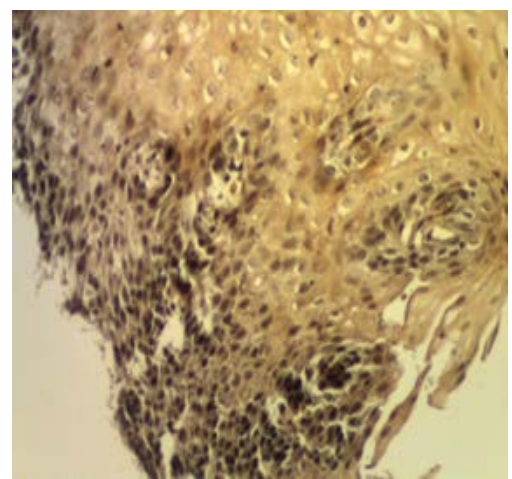

Fig. 8. Esophagus mucosa of sickly children with the GERD. Basal cell hyperplasia of the stratified squamous epithelium. Van Gieson $(10 \times 10)$

Along with the dystrophic changes in the cells of the stratified squamous epithelium, infiltration of the esophagus mucosa by lymphocytes, plasma cells, occasionally by single eosinophil and neutrophil cells (Fig. 7) was identified in all observations. Inflammatory infiltration was observed in the depth of the epithelium, in the papillary area, in the submucous layer with dilatation and plethora of the mucosa vessels (Fig. 10).

The frequency of verification of morphological signs of the distal esophagus mucosa lesions in sickly adolescents is given in Table $\mathbf{1}$. 


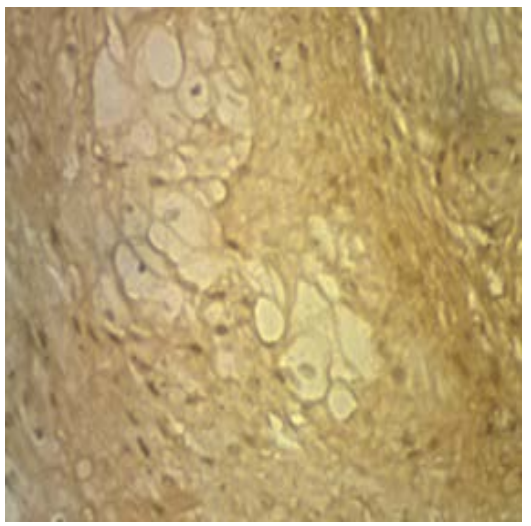

Fig. 9. Esophagus mucosa of sickly children with the GERD. Focuses of the balloon dystrophy of the stratified squamous epithelium. Van Gieson $(10 \times 10)$

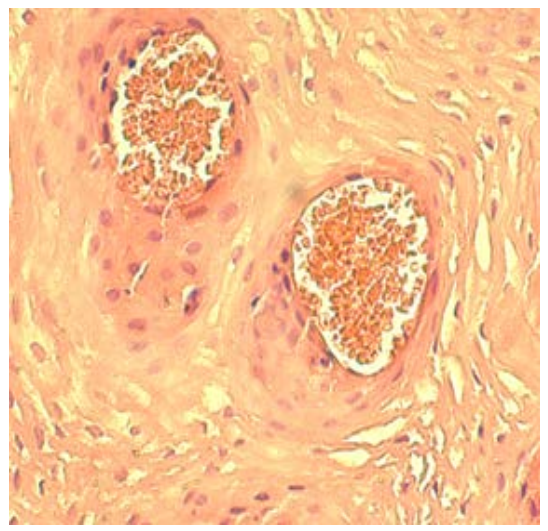

Fig. 10. Esophagus mucosa of sickly children with the GERD. Mucosa dilatation and plethora of vessels. Hematoxylin \& eosin $(10 \times 20)$

\section{Table 1}

Morphological signs of the distal esophagus mucosa lesions with diagnosed GERD in children sickly with acute respiratory disease

\begin{tabular}{lcc}
\hline \multicolumn{1}{c}{ Morphological signs } & Abs. & $\%$ \\
\hline Occurrence of erosions: & 30 & 33.3 \\
- superficial & 24 & 26.7 \\
- deep & 6 & 6.6 \\
Thinning of epithelium & 54 & 60.0 \\
Thickening of epithelium & 12 & 13.3 \\
Alternation of the areas of thinning and thickening of the epithelium & 24 & 26.7 \\
Basal cell hyperplasia & 42 & 46.7 \\
Papillae elongation & 30 & 33.3 \\
Dystrophy of the epithelium & 90 & 100.0 \\
Parakeratosis & 12 & 13.3 \\
Inflammatory infiltration & 90 & 100.0 \\
Dilatation and plethora of vessels & 42 & 46.7
\end{tabular}


As we see, erosive reflux esophagitis (erosive form of the reflux disease) was detected in 30 observations (33.3\%), of which superficial - in 24 (26.7\%), deep - in 6 (6.6\%) cases. Often, instead of erosion, there was a thinning of the epithelial layer (54 cases, $60 \%$ ) or its focal thickening (12 observations, $13.3 \%$ ).

In 24 case $(26.7 \%)$, there were areas of thinning of the esophagus mucosa, which alternated in some places with its thickening. Hyperplasia of the basal cells of the esophagus mucosa was observed in 42 observations (46.7\%), sometimes hyperplasia was accompanied by an increase in the number of papillae and their elongation (30 cases, $33.3 \%$ ).

Dystrophic changes in keratocytes in the superficial parts of the stratified squamous epithelium were found in all patients (90 people, $100.0 \%$ ), with focal parekeratosis in $13.3 \%$ of patients (12 people). Infiltration of the esophagus mucosa was verified in all cases (90 patients, $100.0 \%$ ), with dilatation and plethora in 42 patients $(46.7 \%)$.

The diagnostic value of the morphological signs of the distal esophagus lesion in children sickly with acute respiratory diseases with diagnosed GERD is presented in Table 2.

Table 2

Diagnostic value of the morphological signs of the distal esophagus lesion in children sickly with acute respiratory diseases with diagnosed GERD, \%

\begin{tabular}{cccc}
\hline Signs & Sensitivity & Specificity & Diagnostic value \\
\hline Occurrence of erosions & 33.3 & 96.0 & 77.4 \\
Thinning of epithelium & 60.0 & 93.3 & 76.7 \\
Thickening of epithelium & 13.0 & 96.0 & 65.0 \\
Basal cell hyperplasia & 47.0 & 93.3 & 75.6 \\
Papillae elongation & 33.3 & 93.3 & 70.8 \\
Dystrophy of the epithelium & 100.0 & 93.3 & 96.8 \\
Inflammatory infiltration & 100.0 & 40.0 & 81.3 \\
Dilatation and plethora of vessels & 47.0 & 86.7 & 66.7
\end{tabular}

Thus, in the morphological study of the biopsy material of children sickly with acute respiratory diseases with diagnosed GERD, the diagnostic sensitivity of the esophagus mucosa lesions in the form of erosions was $33.3 \%$, the specificity was $96.0 \%$, and the total diagnostic value was $77.4 \%$. Similar results were obtained for such a morphological feature as the mucosa epithelium papillae elongation - sensitivity $-33.3 \%$, specificity $-93.3 \%$, total diagnostic value $-70.8 \%$.

Instead, the thinning of the epithelium in children sickly with acute respiratory diseases with diagnosed GERD had a greater diagnostic value $(76.7 \%)$ compared with signs of thickening of the epithelium (65.0\%) and epithelium basal cell hyperplasia $(75.6 \%)$, with a sensitivity of $47 \%$ and specificity of $93.3 \%$.

The highest coefficients of diagnostic value in sickly children with diagnosed GERD were obtained for such signs as dystrophy of the epithelium (sensitivity - $100.0 \%$, specificity $-93.3 \%$, total value $-96.8 \%$ ) and inflammatory infiltration (sensitivity $-100.0 \%$, specificity $-40.0 \%$, total value $-81.3 \%$ ).

Consequently, the findings are partly consistent with the generally accepted recommendations for the evaluation of the reflux esophagitis, where, regardless of the endoscopic diagnosis for the morphological confirmation of the erosive esophagitis, the following criteria are required:

1) papillae enlargement of more than $2 / 3$ of the thickness of the mucosa;

2) hyperplasia of the basal layer;

3) intraepithelial granulocytosis and even single neutrophil or eosinophil cells [6,9].

For children sickly with acute respiratory diseases with diagnosed GERD, we have established a slightly different trend. Particularly, in this group, not the thickening of the epithelium, 
hyperplasia of the basal layer and papillae elongation, but thinning (sensitivity $-60.0 \%$, specificity $-93.3 \%$, total value $-76.7 \%$ ) and dystrophy of the epithelium (sensitivity $-100.0 \%$, specificity $-93.3 \%$, total value $-96.8 \%$ ) have the largest value.

According to the existing data in literature regarding morphological changes of the esophagus mucosa for diagnosing GERD is important: capillary dilation, intraepithelial lymphocytes, balloon dystrophy of squamous epithelium cells [13].

We also identified the above features in the examined group of children sickly with acute respiratory diseases with diagnosed GERD.

In the event that the endoscopic examination does not reveal any apparent defects in the mucosa, signs of inflammation may still be detected in the biopsy material. In children sickly with acute respiratory diseases with diagnosed GERD, the sensitivity of this sign is $100.0 \%$, and the overall diagnostic value is $81.4 \%$.

\section{Discussion}

Before discussing the results of 60 adolescents (10 to 16 years old, average age $13.1 \pm 3.54$ years) that were observed at the Children's Clinical Hospital No. 9 of Kyiv and on the basis of the Department of Pediatrics No. 1 Primary Health Care Center No. 4 of the Desnianskyi district of Kyiv the following should be noted. At present, there is no, and probably, cannot be, the unified criteria for evaluating the results of the study of morphological changes in gastroesophageal reflux disease in the biopsy materials of the esophagus in adolescents sickly with acute respiratory diseases.

For the endoscopic classification of esophagitis in academic research in adults and children, the [9] Savary-Miller classifications in the Carisson and [10] modifications are used. However, the endoscopically normal mucus of the esophagus does not exclude the diagnosis of GERD or esophagitises of other etiologies.

The study does not claim exclusion because it involves a limited number of individuals and the tests were made on materials from two medical institutions, which in some way increases the percentage of statistical error.

\section{Conclusion}

1. Evaluation of morphological changes in the distal esophagus mucosa should take into account the following features: erosions, thinning, thickening and dystrophy of the epithelium, assessment of papillae elongation, inflammatory infiltration and hyperplasia of the basal layer, as well as vascular plethora.

2. The peculiarity of the morphological manifestations of the GERD in children sickly with acute respiratory diseases is dystrophic changes in keratocytes of the superficial layers of the stratified squamous epithelium, which are detected in $100.0 \%$ of patients (specificity $-93.3 \%$, total value $-96.8 \%$ ), with foci of parakeratosis in $13.3 \%$ of cases.

3. For the further research, it is recommended to continue the study of morphological changes in gastroesophageal reflux disease in the esophagus biopsy material in adolescents sickly with acute respiratory diseases with diagnosed GERD.

\section{References}

[1] Boyarska, L. M., Ivanova, K. O., Skalozubova, I. B. (2012). Clinical and Functional Features of Gastroesophageal Reflux Disease in Children and Adolescents. Pathology, 1 (24), 26-30.

[2] Zhykhareva, N. S. (2013), Gastroesophageal Reflux Disease in Children. Medical Council, $3,34-41$.

[3] Tang, M., Blake, K. V., Lima, J. J., Mougey, E. B., Franciosi, J., Schmidt, S. et. al. (2019). Genotype tailored treatment of mild symptomatic acid reflux in children with uncontrolled asthma (GenARA): Rationale and methods. Contemporary Clinical Trials, 78, 27-33. doi: http://doi.org/10.1016/j.cct.2019.01.009

[4] Chen, X., Peng, W.-S., Wang, L. (2019). Etiology analysis of nonspecific chronic cough in children of 5 years and younger. Medicine, 98 (3), e13910. doi: http://doi.org/10.1097/md.0000000000013910

[5] Tack, J., Pandolfino, J. E. (2018). Pathophysiology of Gastroesophageal Reflux Disease. Gastroenterology, 154 (2), 277-288. doi: http://doi.org/10.1053/j.gastro.2017.09.047 
[6] Ruigómez, A., Wallander, M.-A., Lundborg, P., Johansson, S., Rodriguez, L. A. G. (2009). Gastroesophageal reflux disease in children and adolescents in primary care. Scandinavian Journal of Gastroenterology, 45 (2), 139-146. doi: http://doi.org/10.3109/00365520903428606

[7] Nakayama, Y., Ida, S. (2017). Endoscopic findings of esophagogastric junction in children. Digestive Endoscopy, 29, 11-17. doi: http://doi.org/10.1111/den.12793

[8] Gyawali, C. P., Fass, R. (2018). Management of Gastroesophageal Reflux Disease. Gastroenterology, 154 (2), 302-318. doi: http://doi.org/10.1053/j.gastro.2017.07.049

[9] Macchini, F., Zanini, A., Pasqua, N., Farris, G., Canazza, L., Gentilino, V. et. al. (2015). Endoscopic Surveillance for Congenital Diaphragmatic Hernia: Unexpected Prevalence of Silent Esophagitis. European Journal of Pediatric Surgery, 26 (3), 291-295. doi: http://doi.org/10.1055/s-0035-1552568

[10] Hoshihara, Y., Iwakiri, K. (2016) Endoscopic classification of reflux esophagitis. Nihon Rinsho, 74 (8), 1262-1267.

[11] Tutar, E., Kutluk, G., Bayrak, N. A., Ataizi Celikel, C., Pehlivanoglu, E., Ertem, D. (2009). What is the diagnostic utility of endoscopic scoring systems in children? The Turkish Journal of Gastroenterology, 24 (1), 22-29. doi: http://doi.org/10.4318/tjg.2013.0700

[12] Numans, M. E., De Wit, N. J. (2003). Reflux symptoms in general practice: diagnostic evaluation of the Carlsson-Dent gastro-oesophageal reflux disease questionnaire. Alimentary Pharmacology and Therapeutics, 17 (8), 1049-1055. doi: http://doi.org/10.1046/j.1365-2036.2003.01549.x

[13] Hoshino, M., Omura, N., Yano, F., Tsuboi, K., Yamamoto, S. R., Akimoto, S. et. al. (2018). Impact of reflux esophagitis on the esophageal function before and after laparoscopic fundoplication. Esophagus, 15 (4), 224-230. doi: http://doi.org/10.1007/s10388-018-0618-8

[14] Kasyap, A. K., Sah, S. K., Chaudhary, S. (2018). Clinical spectrum and risk factors associated with asymptomatic erosive esophagitis as determined by Los Angeles classification: A cross-sectional study. PLOS ONE, 13 (2), e0192739. doi: http://doi.org/10.1371/journal.pone.0192739

[15] Vakil, N. (2010). Disease definition, clinical manifestations, epidemiology and natural history of GERD. Best Practice \& Research Clinical Gastroenterology, 24 (6), 759-764. doi: http://doi.org/10.1016/j. bpg.2010.09.009

[16] Houghton, L. A., Smith, J. A. (2017). Gastro-oesophageal reflux events: just another trigger in chronic cough? Gut, 66 (12), 2047-2048. doi: http://doi.org/10.1136/gutjnl-2017-314027

[17] Evsyutina, Yu. V., Trukhmanov, A. S., Ivashkin, V. T. (2015). Systemic Immune Response in Patients with Gastroesophageal Reflux Disease. Russian Journal of Gastroenterology, Hepatology and Coloproctoly, 5, 32-38.

[18] Leason, S. R., Barham, H. P., Oakley, G., Rimmer, J., DelGaudio, J. M., Christensen, J. M. et. al. (2017). Association of gastro-oesophageal reflux and chronic rhinosinusitis: systematic review and meta-analysis. Rhinology Journal, 55 (1), 3-16. doi: http://doi.org/10.4193/rhin16.177

[19] Friesen, C. A., Rosen, J. M., Schurman, J. V. (2016). Prevalence of overlap syndromes and symptoms in pediatric functional dyspepsia. BMC Gastroenterology, 16 (1), 75. doi: http://doi.org/10.1186/ s12876-016-0495-3 